\title{
AUTISM AND PEDIATRIC DENTISTRY: A LITERATURE REVIEW
}

\author{
Eman A. El Ashiry*
}

\begin{abstract}
Typically diagnosed in the first three years of life, autism is a complex developmental disability. It affects the individual's communication and interaction abilities which present significant challenges in providing oral care. The objective of this literature review was to discuss prevalence, diagnosis, etiology, medications and dental problems for autism. Using the Cochrane library database, PubMed, the EviDence search engine, Google scholar, online review of English scientific papers from 2009 to 2019 was carried out. The keywords used were autism; general management; pediatric dentistry; review. In the present literature review, 57 articles were eventually included after eliminating copies. Pediatric dentists should be mindful that early diagnosis and treatment, effective communication skills and follow-up of youngsters with autism remain the best methods to ensuring improved psychological well-being for patients and, eventually, a better living.
\end{abstract}

Keywords: autism; pediatric dentistry; literature review

\section{INTRODUCTION}

Oral health is an important part of health at large. Oral issues can be the source of pain, suffering and functional impairment and can affect the total "QOL" and well-being of the individual. ${ }^{1}$ "OHRQOL" was described as "a multidimensional construct that reflects people's comfort when eating, sleeping, and engaging in social interaction; their self-esteem; and their satisfaction with respect to their oral health". ${ }^{2}$

The danger of dental problems is high in people with "SHCN". ${ }^{2}$ Studies on youngsters with "SHCN" have shown that these youngsters sustain a diversity of dental signs, every day life issues, and matters that contribute to the dental health of the child and have an effect on the "QOL" of both the child and the family. ${ }^{3}$

Autism is "a complex developmental disability that typically appears during the first three years of life and affects a person's ability to communicate and interact with others". ${ }^{4}$

The term autism spectrum disorders "ASDs" refers to the three disorders: Autism, Asperger's Disorder and PDD-NOS. .,6,7

* Pediatric Dentistry Department, Faculty of Dentistry, King Abdulaziz University, KSA and Pedodontic Department, Faculty of Dental Medicine for Girls Al Azhar University, Egypt 
Those who are working with children are likely to encounter patients with autism. However, because of their communication and behavioral problems these children face notable defies in receiving dental aid. Youngsters with autism will show up some unusual oral health conditions that may be attributed to their use of medications or to their practice of damaging oral habits. ${ }^{8}$

Other oral problems include, delayed tooth eruption due to phenytoin- induced gingival hyperplasia, as phenytoin may be prescribed for people with autism. Trauma and injury to the mouth may be seen in those with seizure disorders or in those who suffer from perversion. ${ }^{9}$

In advanced countries, their decay and gum disease rates have been similar to those in common people. ${ }^{9}$ In Kingdom of Saudi Arabia, dental health research in autistic youngsters have been minimal. The autistic children in one sample in Riyadh did not show a statistically notable difference from the global cohort identified in former research. ${ }^{10}$

\section{AIM}

The objective of this literature review was to discuss prevalence, diagnosis, etiology, medications and dental problems for autism.

\section{MATERIALS AND METHODS}

Using the Cochrane library database, PubMed, the EviDence search engine, Google scholar, online review of English scientific papers from 2009 to 2019 was carried out. The keywords used were autism; general management; pediatric dentistry; review.

\section{RESULTS}

In the present literature review, 57 articles were eventually included after eliminating copies.

\section{DISCUSSION}

Autism was initially described in 1943 , by Leo Kanner, a psychiatrist at Johns Hopkins University. He identified autism in a small group of children who were found to show total indifference to others and intense aloofness. ${ }^{11}$

The diagnosis of autism is typically attained in a child or adult when abnormalities are seen in three behavioral domains: "social development, communication, and repetitive behavior/obsessive interests". ${ }^{12}$

\section{Social Impairment}

From infancy, limitations in interpersonal skills are apparent such as lack of attention seeking, direct eye contact, or reaction to mother's voice or to smiles. The baby with this disorder does not reach out to be picked up, point to object to the parent or interact in simple imitation games. ${ }^{13}$

Young children with autism seem to be in their own world. They don't join in group play or share in other children's interests. They also suffer from deficits in the normal process of empathy, relative to mental age "mind blindness". They do not seem to be aware of the feelings, intentions, and beliefs of others and that these views may be different from their own. This consequently often results in social conflicts. $^{14}$

In the teenage and young adult years, they usually favor solitary activities rather than develop friendships. They continue to have no empathy with others and show an interest in sharing their successes with others. ${ }^{15}$

\section{Communication Impairment}

Verbal and nonverbal communication skills are either impaired or missing. There is a lack of drive to connect or combine words with body language in those who are verbal "about 50 percent," and there is a tendency towards one-sided conversation and 
pronoun reversal. Their language would probably be repetitive and non-responsive to the context.

Moreover, they tend to be confused and use made-up word "neologisms". Event like immediate echolalia "the unintentional repetition of things that have been heard recently," delayed echolalia "repetition of things heard in the past" and unusual alteration of speech tone, stress and rhythm may further obscure the meaning of speech..$^{16,17}$

\section{Repetitive Behavior/Obsessive Interests}

Individuals with autism display "self-stimulatory" behaviors such as body rocking, flapping the hands, and finger flicking. These movements could be set off by triggers like noise, stress or excitement. Furthermore, these children often persist on rigid routines; any changes in their routines may upset them and may even provoke tantrums. They also dislike invasion of personal space and are resistant to being rushed. ${ }^{15}$

People with autism show obsessive interests for instance they may become fixated by the sensory features of things such as parts of the body or buttons on appliances. Their play shows lack of creativity. They may compulsively line up blocks in rows instead of building with them. With age, they may become fascinated with structures that function according to fixed rules, such as: "trains, numbers, letters and planetary movements". ${ }^{15}$

\section{Cognitive Impairment}

About $70 \%$ of kids with autism suffer from cognitive impairment, which in 40 percent of cases is severe. Many people with autism work within the spectrum of "strong" mental retardation. ${ }^{15}$ However, when the disorder occurs in a female, the degree of mental retardation is usually more severe. ${ }^{18}$

\section{Other Problems}

Many attitude signs of autism, especially in youngsters, include "temper tantrums" and may exhibit "SIB" violent and self-injurious behavior, with age. Seventy percent of autistic patients have SIB.${ }^{19}$ Other comorbid conditions include attention deficit hyperactivity disorder, obsessive compulsive disorder, anxiety disorders, mood disorders, and schizophrenia. ${ }^{20}$ In addition, "sometimes great mal" seizures are normal, with more than $30 \%$ of adolescents having 2 or more epileptic seizures..$^{15}$ The seizures in these children usually present in two peaks: before five years of age and during the adolescence years. ${ }^{21}$

\section{Autism Spectrum Disorders "ASDs"}

According to the Diagnostic and Statistical Manual of Mental Disorders, 4th Edition, Text Revision "DSM-IV-TR", Pervasive Developmental Disorders is an umbrella term that includes five disorders which are: "Autistic Disorder, Rett's Disorder, Childhood Disintegrative Disorder, Asperger's Disorder, and Pervasive Developmental Disorder-Not Otherwise Specified (PDD-NOS)". ${ }^{22}$

Together, Autism, Asperger's Disorder and PDD-NOS make the three recognized disorders in the autism spectrum and are termed Autism Spectrum Disorders. ${ }^{23}$ The most serious of ASD's is classic autism. Youngsters with Asperger's syndrome have deficient social cleverness and low capability to reveal sympathy but have common intelligence and language cleverness, and usually show peculiar interests, for example, they will try to read everything they can about a topic, ${ }^{24}$ they take speech literally, and often have problems understanding other people's body language and facial expressions..$^{15}$ The term "PDD-NOS" is used when not meeting the full set of criteria for autism or Asperger's syndrome. ${ }^{25,26,27}$

\section{Prevalence}

The prevalence of ASDs in developed countries is approximately 60 per 10,000 , with males more than females. ${ }^{6}$ In the Middle East, the incidence of autism research has been particularly rare. 
One rough estimate of the prevalence of autism in Saudi Arabia is 18 per $10,000 .^{7}$

\section{Diagnosis}

There are no established accurate clinical diagnostic tests for ASD, "e.g. blood tests or brain scans," nor are prenatal screening measures available to assist expecting parents. ${ }^{8,15}$ The diagnosis is focused on behavior, rather than on cause or mechanism..$^{28}$ An evaluation by a pediatrician, psychologist, or psychiatrist is usually required for the definitive diagnosis of ASDs. The diagnosis is made by an analysis process which includes the clinical and developmental history, receptive and expressive language skills evaluation, and cognitive function tests. ${ }^{8,29,30}$

There are numerous diagnostic instruments. In autism research, there are two frequently used instruments, one is a semi structured parent interview, which is the "Autism Diagnostic Interview-Revised (ADI-R)", and the other, the "Autism Diagnostic Observation Schedule (ADOS)", diagnoses autism through observation and interaction with the child. To assess autism severity in clinical environments, the "Childhood Autism Rating Scale (CARS)" is commonly utilized and is based on observation of the children. ${ }^{31}$

\section{Etiology}

ASD etiology is a riddle. Highly respected researchers believe that there could be more than one cause since it can have different manifestations. Several factors have been implicated such as: "genetics, environmental poisons, neurologic psychopathy, dietary deficiencies, and allergies". ${ }^{29}$ Immunizations with the measles-mumps-rubella vaccines have been studied for their possible link to the increase in autism but have failed to confirm this link. ${ }^{32}$

There is evidence of multiple genetic factors interacting as the autism's primary causative determinants. Two conditions, "complex tuberous sclerosis, and fragile X syndrome" are often associated with autism but represent only a small fraction of cases. Despite the preponderance of males indicating an X-linked condition and the presence of a few well-characterized X-linked disorders, the prevalence of male-to-male transmission in some families prevents $\mathrm{X}$-linkage from being the dominant mode of inheritance. ${ }^{32}$

The rate of recurrence in siblings of children with autism is around $2 \%$ to $8 \%$ which is higher than the general population's prevalence rate but lower than in single-gene diseases. ${ }^{32}$ There are suggestions that "idiopathic" autism is due to interactions between multiple genes, while, the variable expression of autism-related traits are a result of epigenetic factors and exposure to environmental modifiers. ${ }^{32}$

An interesting finding was that there is an accumulation of evidence suggesting that advanced parental age and "birth weight and length of gestation and intrapartum hypoxia" disorders are associated with a high chance of autism and ASD. ${ }^{33}$

Increased head size was initially noted by Kanner, in several of his patients ${ }^{11}$ and has continued to be a frequent physical finding in youngsters with ASDs. ${ }^{32}$

Neuropathological examinations of brain tissue have revealed several abnormalities in people with autism ${ }^{32}$ including: "The Purkinje cells in the cerebellum were found to be decreased in number, the entorhinal cortex neurons were small and closely packed and the amygdala nuclei were positioned medially, the temporal and frontal lobes had abnormalities in the minicolumns of the cortex, the diagonal band of Broca nucleus, deep cerebellar nuclei, and inferior olive showed developmental changes in the size and number of cells and abnormalities in the brainstem and malformations in the neocortex".

Magnetic resonance imaging "MRI" performed to define the neuropathology of ASDs reviled 
structural abnormalities of the limbic system "the amygdala, cingulate gyrus and hippocampus". The "limbic system" is in control of social and emotional attitude. For children with autism, the amygdala is initially greater than that in typically developing children, but it does not respond to the normal volume increase associated with age afterwards. Kids with autism also had greater right hippocampal volume. ${ }^{34}$

\section{Medications for Autism and their Dental Impli- cations}

Children with autism often require comprehensive management with the ultimate aim to achieve independence in daily living activities and selfcare. Parental counseling, special teaching, speech therapy, and social skills training may be needed for their management. Medicines are commonly utilized to manage individual conduct that intervene with an autistic person's developmental activities or that can cause domestic status, or to treat some of the autism-related symptoms. ${ }^{15}$

Antipsychotic drugs are the commonly prescribed drugs. They are used to manage symptoms of irritability, repetitive behaviors, SIB, aggression, delusions and hallucinations. ${ }^{17}$ Around $45 \%$ of youngsters with ASDs are managed with psychotropic medicines. ${ }^{35}$ Other drugs include anticonvulsants to manage aggression, mood fluctuations and seizures; antidepressants to manage repetitive thoughts and attitude, depression, anxiety and fear; central nervous system "CNS" stimulants to calm hyperactivity and enhance attention and clonidine a centrally acting antihypertensive drug to calm hyperactivity and reduce impulsivity. ${ }^{15}$

It is important for dentists to be familiar with the features and the possible orofacial and systemic reactions of the drugs usually given to children with ASD, as many of them have adverse effects or may adversely interact with dental therapeutic agents. ${ }^{17}$ Such drugs have orofacial adverse effects including: "xerostomia, sialorrhea, dysphagia, sialadenitis, dysgeusia, stomatitis, gingivitis, gingival enlargement, glossitis, bruxism, edema and discoloration of the tongue". ${ }^{15}$

\section{Autism in Dentistry}

Those who are dealing with youngsters probably meet patients with autism. Of the healthcare providers, dentists may often be the first to realize an extraordinary pervasive behavioral disorder in a 1-2-year-old child..$^{29}$ In a survey to investigate the professional conduct and demeanor of pediatric and general dentists towards ASD patients in the United States, it was found that $32 \%$ of general dentists and $89 \%$ of pediatric dentists treat ASD youngsters. ${ }^{36}$

Children with autism may display few unusual oral health conditions. Some problems may be attributed to the use of medications and damaging oral habits "bruxism; tongue thrusting; SIB and pica". ${ }^{9}$ Seventy five percent of factitial injuries are located in the head and neck region. ${ }^{37}$ It was found that, high levels of impulsivity and stereotypy were significant predictors of SIBs in individuals with ASD ${ }^{38}$ In addition, hyperactivity, negative affect "emotion" and low levels of ability and speech were also associated with SIB. ${ }^{39}$ Several methods have been proposed to reduce SIB in children with autism including: behavioral techniques medications and, for those who can tolerate it, a mouth guard can be prescribed when indicated for patients who have problems with SIBs involving the mouth. ${ }^{9,40}$

Regarding caries and periodontal disease in people with autism, the rates are equivalent to those in common people. ${ }^{9}$

In Kingdom of Saudi Arabia, the oral health status, oral demands, behaviors and behavioral attitudes towards oral management of a number of autistic youngsters visiting a rehabilitation center in Riyadh were evaluated in a study. ${ }^{10}$ Compared with other healthy children studies in the Riyadh region, the results of the study showed decreased decay 
percentage in the autistic test group, but this was not generalized because of the children's convenience sample. It was revealed that, in the report, the dental health condition, attitudes and behaviors of the studied youngsters with autism were same as those of other autistic youngsters worldwide.

Other international studies found dental caries to be comparable between the autistic and non- autistic populations. ${ }^{11}$ They reported that decay rates of noninstitutionalized autistic youngsters were similar to those of unaffected youngsters. ${ }^{41}$ Similarly, in Sweden, they found similar dental status of autistic and healthy children aged 3-19 years old.$^{42}$ However, a study in Melbourne, Australia, on youngsters with disabilities, autistic children, showed that youngsters with disabilities had increased dental decay than others. ${ }^{43}$

On the other hand, two studies, one was comparing children with autistic disorder "AD" to normal children in Istanbul, Turkey ${ }^{44}$ and the other in Boston, $\mathrm{USA}^{45}$, comparing children with ASDs to those without them, revealed that those with $\mathrm{AD}$ and ASD had lower experience of caries. Another study done in a population of autistic children in Japan found that their caries experience in 1980 was comparable to that of unaffected children in 1981, and that, the dental status in the children with autism improved in 1995 reaching to lower caries prevalence and severity compared to those of unaffected children in 1993. ${ }^{46}$

The average prevalence of decay among youngsters with autism in the United Arab Emirates was reported to be $77 \%$, whereas for autistic youngsters aged 11-15 years the restorative index "the restorative care of those who have suffered the disease" and met the need index "an indicator of an individual's treatment" was small. ${ }^{47}$

A study showed that the latter group had substantially more oral injuries, an irregular salivary flow and developmental abnormalities when comparing children with ASD to those with other developmental disabilities. Kids with an ASD showed clinically visible symptoms with a rate of: plaque 85 percent, gingivitis 62 percent, and caries 21 percent. Around half the kids with ASD is protective by mouth. ${ }^{48}$

When parents notified their child's dental condition and needs, a study in Rochester, USA, showed that, the teeth were reported as in outstanding condition in $52 \%$ of the autistic youngsters and $69 \%$ of the youngsters without autism. The dental status was found to be comparable between the autistic children and the non- autistic children who had fair or poor teeth. ${ }^{49}$

A research assessing the dental condition of youngsters with $\mathrm{AD}$ in Chennai, India, found that in the primary dentition, the incidence of dental caries "24\%" was significantly higher than the other dental status. In the youngsters with mixed dentition, gingivitis " $50 \%$ " was prevalent, while in children with permanent dentition, malocclusion " $71.15 \%$ " and gingivitis " $48.96 \%$ " were prevalent. ${ }^{50}$

Bruxism is reported in 20 to 25 percent of children with autism. ${ }^{10}$ They also generally tend to pouch their food instead of swallowing it because of poor tongue coordination. ${ }^{51}$

Some oral disorders include oral trauma and injury caused by accidents or falls from coma or physical abuse. People with developmental disabilities are abused more frequently than the general population. Phenytoin is frequently prescribed for autistic individuals, which may lead to phenytoin-induced gingival hyperplasia and delayed tooth eruption. ${ }^{9}$

The goal in daily oral care of children with autism is to encourage independence in the daily oral hygiene of these children. This could be accomplished by customized recommendations and hands-on demonstrations, and when needed, dental professionals may advise the use of modified toothbrushes and floss holders to ease the process of oral hygiene. ${ }^{9}$ 
In kids with ASD, information obtained visually is rapidly comprehended and is retained longer than verbally received information. Therefore, the use of visual supports can be useful in teaching children with autism oral hygiene procedures. ${ }^{52}$ Visual supports involve visual schedules which are breaking down large tasks into separate steps, and social stories, which are short stories written from the child's view describing a social situation, person, skill, event or concept in terms of relevant cues and appropriate social response..$^{53}$ The story may incorporate pictures about the situation and it is repeatedly read to the child so it becomes a routine for the child and may be applied to that situation when it occurs. ${ }^{52}$

In one prospective study, oral hygiene was improved in 14 children with autism over a period of 12 months by the use of a series of pictures that were placed in the bathrooms or wherever oral hygiene was performed displaying a structured method and technique of tooth brushing. After 18 months, most parents reported that maintenance of good oral hygiene became easier than before the study. This emphasizes the usefulness of visual pedagogy in enhancing oral hygiene and also in introducing dentistry to children with autism. ${ }^{54}$

For those who just cannot maintain oral hygiene independently, careful demonstrations for the parents of oral hygiene techniques tailored to meet the individual needs of each child using sitting or standing positions for the parents with attention to consistency "same location, time and position" are the key approaches to improve the quality and the oral hygiene experience to both the youngsters and their parents. ${ }^{9}$

The most significant challenges in providing dental care and treatment for this group of children are communication and behavioral problems. ${ }^{9}$ Due to the difficulties to gauge and control the sedation level and the atypical responses in some cases using intravenous sedative agents, the use of general anesthesia has been recommended to perform dental treatments that require long and involved procedures in patients with autism. ${ }^{15}$

However, solid knowledge and precautions concerning their physical and biomedical problems, is essential to prevent the anesthetic from representing another toxic insult to children with autism. Autistic youngsters may have certain problems like, gastrointestinal dysfunction, mitochondrial dysfunction, oxidative stress and impaired detoxification systems..$^{55}$

Methylation problems in autistic individuals may cause increased oxidative stress. ${ }^{56} \mathrm{~A}$ study described a "redox/methylation hypothesis of autism," in which environmental factors initiate oxidative stress, in genetically vulnerable individuals, which cause impaired methylation and neurological deficits. ${ }^{57}$ Therefore, oxidative stress resulting from general anesthesia should be minimized. Commonly used anesthetics may result in B12 depletion, affect methylation and add to the toxic load. In addition, in patients with mitochondrial problems, there might be a risk with the use of certain anesthetics..$^{55}$

In a study which aimed to identify mental health publications in Arab countries cited in PubMed from 1987 to 2002, the total number of mental health research citations on child and adolescent mental health published in Arab countries found was 338. Child psychiatry, especially child autism and attention deficit hyperactivity disorder, were not gaining much interest from Arab researchers. ${ }^{27}$

Murshid's ${ }^{10}$ recent report on the characteristics and dental experiences of a group of autistic children in Saudi Arabia's three major cities: Riyadh, Dammam, and Jeddah. Most of the "76.2 percent" children included in the report were diagnosed with autism before the age of five years. Although 33\% of children received general anesthesia treatment, more than half of " $53.7 \%$ " had no prior dental experience. 
Striding to achieve a difference in the dental health of autistic youngsters may be difficult at first, but with determination and persistence, promising results and worthy rewards can be achieved. Through assessing the oral health status and the OHRQOL of this vulnerable group of children, a sharper picture of the extent of their oral health problems can be portrayed. This can direct us in developing a targeted strategy towards this special group, one that can have a significant effect on their dental health and ultimately on their QOL as well.

\section{CONCLUSION:}

Pediatric dentists should be mindful that early diagnosis and treatment, effective communication skills and follow-up of youngsters with autism remain the best methods to ensuring improved psychological well-being for patients and, eventually, a better living.

\section{REFERENCES}

1. Petersen PE. (2003), The world oral health report 2003: continuous improvement of oral health in the 21 century the approach of the WHO Global Oral Health Programme. Community Dent Oral Epidemiol, 31 Suppl 1:3-23.

2. U.S. Dept of Health and Human Services. (2000), Oral health in America: A report of the Surgeon General. NIH Publication 00-4713.Rockville, Maryland: National Institute of Dental and Craniofacial Research, National Institutes of Health, 7.

3. Baens-Ferrer C, Roseman MM, Dumas HM, Haley SM. (2005), Parental perceptions of oral health-related quality of life for children with special needs: impact of oral rehabilitation under general anesthesia. Pediatr Dent, 27(2):137-142.

4. Autism Society of America. (2012), About autism. Autism society. http://www.autism-society.org/about-autism/.

5. Johnson CP, Myers SM, Council on Children with Disabilities. (2007), Identification and evaluation of children with autism spectrum disorders. Pediatrics, 120(5):1183-1215.

6. Newschaffer CJ, Croen LA, Daniels J Giarelli E, Grether JK, Levy SE, et al. (2007), The epidemiology of autism spectrum disorders. Annu Rev Public Health, 28:235-358.
7. Al-Salehi SM, Al-Hifthy EH, Ghaziuddin M. (2009), Autism in Saudi Arabia: presentation, clinical correlates and comorbidity. Transcult Psychiatry, 46(2):340-347.

8. Berman MH. (2010), Autistic spectrum disorder: the challenge for dentists. Dent Today, 29(10):96-98, 100, 102; quiz 103, 194.

9. U.S. Department of Health and Human Services. (2009), Practical Oral Care for People with Autism. NIH Publication 09-5190. Bethesda, Maryland: National Institute of Dental and Craniofacial Research, National Institutes of health.

10. Murshid EZ. (2005), Oral health status,dental needs habits and behavioural attitude towards dental treatment of a group of autistic children in Riyadh, Saudi Arabia. Saudi Dent J, 17: 132-9.

11. Kanner L. (1943), Autistic disturbances of affective contact. Nerv Child, 2:217-250.

12. Baron-Cohen S. (2004), The cognitive neuroscience of autism. J Neurol Neurosurg Psychiatry, 75(7):945-948.

13. Rogers SJ, Hepburn SL, Stackhouse T, Wehner E. (2003), Imitation performance in toddlers with autism and those with other developmental disorders. J Child Psychol Psychiatry, 44(5):763-781.

14. Baird G, Cass H, Slonims V. (2003), Diagnosis of autism. BMJ, 327(7413):488- 493.

15. Friedlander AH, Yagiela JA, Paterno VI, Mahler ME. (2006), The neuropathology, medical management and dental implications of autism. J Am Dent Assoc, 137(11):15171527.

16. Bishop DV. (2003), Autism and specific language impairment: categorical distinction or continuum?.Norvartis Found Symp, 251:213-26. ; discussion 226-234, 281-297.

17. Boraz RA. (1989), Dental care for the chronically ill child. Pediatrician, 16 (3- 4):193-199.

18. Fombonne E. (2002), Epidemiological trends in rates of autism. Mol Psychiatry, 7(supplement 2): S4-S6.

19. Howlin P. (1993), Behavioral techniques to reduce self-injurious behaviour in children with autism. Acta Paedopsychiatrica, 56(2): 75-84.

20. Stahlberg 0, Soderstrom H, Rastam M, Gilberg C. (2004), Bipolar disorder, schizophrenia, and other psychotic disorders in adults with childhood onset ADIHD and/or autism spectrum disorders. J Neural Transm, 111(7):891-902. 
21. Charles JM. (2010), Dental care in children with developmental disabilities: attention deficit disorder, intellectual disabilities, and autism.J Dent Child, 77(2):84-91.

22. American Psychiatric Association. (2000), Diagnostic and Statistical Manual of Mental Disorders, 4th Edition, Text Revision (DSM-IV-TR). Washington, DC: American Psychiatric Publishing.

23. John MT, Hujoel P, Miglioretti DL, LeResche L, Koepsell TD, Micheelis W. (2004), Dimensions of oral health-related quality of life. J Dent Res, 83(12):956-960.

24. Spence SJ, Sharifi P, Wiznitzer M. (2004), Autism spectrum disorders: screening, diagnosis, and medical evaluation. Semin Pediatr Neurol, 11(3):186-195.

25. Subramaniam P, Gupta M. (2011), Oral health status of autistic children in India. J Clin Pediatr Dent, 36(1):43-47.

26. Nowak AJ. (2002), Patients with special health care needs in pediatric dental practices. Pediatr Dent, 24:227-228.

27. Afifi MM (2005), Mental health publications from the Arab world cited in PubMed, 1987-2002. East Mediterr Health J, 11(3):319-328.

28. London E. (2007), The role of the neurobiologist in redefining the diagnosis of autism. Brain Pathol, 17(4):408-411.

29. Loo CY, Graham RM, Hughes CV. (2008), The caries experience and behavior of dental patients with autism spectrum disorder. J Am Dent Assoc, 139(11):1518-1524.

30. Lowe O, Lindemann R. (1985), Assessment of the autistic patient's dental needs and ability to undergo dental examination. ASDC J Dent Child, 52(1):29-35.

31. Volkmar F, Chawarska K, Klin A. (2005), Autism in infancy and early childhood. Annu Rev Psychol, 56:315-36. A partial update is in: Volkmar FR, Chawarska K. (2008), Autism in infants: an update. World Psychiatry, 7(1):19-21.

32. Muhle R, Trentacoste SV, Rapin I. (2004), The genetics of autism. Pediatrics, 113(5): e472-486.

33. Kolevzon A, Gross R, Reichenberg A. (2007), Prenatal and perinatal risk factors for autism: a review and integration of findings. Arch Pediatr Adolesc Med, 161(4):326-333.

34. Schumann CM, Hamstra J, Goodlin-Jones BL, Lotspeich LJ, Kwon H, Buonocore MH, et al. (2004), The amygdala is enlarged in children but not adolescents with autism; the hippocampus is enlarged at all ages. J Neurosci, 24(28):6392-6401.
35. Centers for Disease Control and Prevention (CDC). (2006), Mental health in the United States: parental report of diagnosed autism in children aged 4-17 years-United States, 2003-2004. MMWR Morb Mortal Wkly Rep, 55(17):481486.

36. Weil TN, Inglehart MR. (2010), Dental education and dentists' attitudes and behavior concerning patients with autism, J Dent Educ, 74(12):1294-1307.

37. Van Moffaert M. (1991), Localization of Self-inflicted dermatological lesions: what do they tell the dermatologist? Acta Derm Venereologica, 156: 23-27.

38. Richman DM, Barnard-Brak L, Bosch A, Thompson S, Grubb L, Abby L. (2012), Predictors of self-injurious behavior exhibited by individuals with autism spectrum disorder. J Intellect Disabil Res, doi: 10.1111/j.13652788.2012.01628.x. [Epub ahead of print].

39. Richards C, Oliver C, Nelson L, Moss J. (2012), Selfinjurious behaviour in individuals with autism spectrum disorder and intellectual disability. J Intellect Disabil Res, 56(5): 476-489.

40. Canitano R. (2006), Self-injurious behavior in autism: clinical aspects and treatment with risperidone. J Neural Transm, 113(3):425-431.

41. Shapira J, Mann J, Tamari I, Mester R, Knobler H, Yoeli Y, et al. (1989), Oral health status and dental needs of an autistic population of children and young adults. Spec Care Dentist, 9(2):38-41.

42. Fahlvik-Planefeldt C, Herrström P. (2001), Dental care of autistic children within the non-specialized Public Dental Service. Swed Dent J, 25(3):113-118.

43. Desai M, Messer LB, Calache H. (2001), A study of the dental treatment needs of children with disabilities in Melbourne, Australia. Aust Dent J, 46(1):41-50.

44. Namal N, Vehit HE, Koksal S. (2007), Do autistic children have higher levels of caries? A cross-sectional study in Turkish children.J Indian Soc Pedod Prev Dent, 25(2): 97-102.

45. Low W, Tan S, Schwartz S. (1999), The effect of severe caries on the quality of life in young children. Pediatr Dent, 21(6):325-326

46. Morinushi T, Ueda Y, Tanaka C. (2001), Autistic children: experience and severity of dental caries between 1980 and 1995 in Kagoshima City, Japan. J Clin Pediatr Dent, 25(4):323-328. 
47. Jaber MA, Sayyab M, Abu Fanas SH. (2011), Oral health status and dental needs of autistic children and young adults. Journal of Investigative and Clinical Dentistry, 2(1):57-62.

48. DeMattei R, Cuvo A, Maurizio S. (2007), Oral assessment of children with an autism spectrum disorder. J Dent Hyg, 81(3):65.

49. Kopycka-Kedzierawski DT, Auinger P. (2008), Dental needs and status of autistic children: results from the National Survey of Children's Health. Pediatr Dent. 30(1): 54-58.

50. Vishnu Rekha C, Arangannal P, Shahed H. (2012), Oral health status of children with autistic disorder in Chennai. Eur Arch Paediatr Dent, 13(3):126-31.

51. Weddell JA, Sanders BJ, Jones JE. (2011), Dental problems of Children Special Health Care Needs. In: Dean JA, Avery DR, and McDonald RE, eds. Dentistry for the child and adolescent, 9th edn. St. Louis: Mosby, 475.
52. Chen MS, Hunter P. (1996), Oral health and quality of life in, New Zealand: a social perspective. Soc Sci Med, 43:1213-1222.

53. Gray C. (1998), Social Stories 101. The Morning News. Mich:Jenison Public Schools, 10(1):2-6.

54. Bäckman B, Pilebro C. (1999), Visual pedagogy in dentistry for children with autism. ASDC J Dent Child, 66(5):325$331,294$.

55. Rankin SC. (2009), Anesthesia and the Autistic Child. The Autism File, 33:14-18.

56. James SJ, Cutler P, Melnyk S, Jernigan S, Janak L, Gaylor DW, et al. (2004), Metabolic biomarkers of increased oxidative stress and impaired methylation capacity in children with autism.Am J Clin Nutr, 80(6):1611-1617.

57. Deth, R, Muratore, C, Benzecry J, Power-Charnitsky, VA, Waly, M. (2008), How environmental and genetic factors combine to cause autism: A redox/methylation hypothesis. Neurotoxicology, 29(1):190-201. 